\title{
How Can Changing the Bridgehead Affect the Properties of Tripodal Ligands?
}

\author{
Alex J. Plajer, ${ }^{[a]}$ Annie L. Colebatch, ${ }^{[a]}$ Felix J. Rizzuto, ${ }^{[a]}$ Patrick Pröhm, ${ }^{[b]}$ Andrew D. Bond, ${ }^{[a]}$ Raúl \\ García-Rodríguez, ${ }^{[\mathrm{c}] *}$ Dominic S. Wright ${ }^{[\mathrm{a}] *}$
}

\begin{abstract}
Although a multitude of studies have explored the coordination chemistry of classical tripodal ligands containing a range of main group bridgehead atoms or groups, there has been no clear answer to the question of how underlying periodic trends affect ligand character and reactivity within a single ligand family. In addition to standard steric and electronic modification of the organic groups themselves, this issue is of key importance in the design and tuning of $C_{3}$-symmetric tripodal ligands for applications in catalysis. A case in point is the extensive family of neutral tris-2-pyridyl ligands $E(2-p y)_{3}$ (e.g., $\left.E=C-R, N, P\right)$, which are closely related to archetypal tris-pyrazolyl borates. With the new 6-methyl substituted ligands $E(6-$ $M e-2-p y)_{3}(E=A s, S b, B i)$ in hand, we have been able to assess the effects of bridgehead modification alone on descending a single group in the periodic table. We show that the primary influence on coordination behaviour is the increasing Lewis acidity (electropositivity) of the bridgehead atom as Group 15 is descended, which not only modulates the electron density on the pyridyl donor groups but also introduces the potential for anion selective coordination behavior.
\end{abstract}

Facially-coordinating chelate ligands have been extensively applied in organometallic and bioinorganic chemistry. ${ }^{[1-6]}$ Preeminent in this area are tris-pyrazolyl borates (Fig. 1a), which have found countless applications as ancillary ligands over the last three decades in catalytic and biomimetic systems. ${ }^{[7]}$ The success and broad-ranging use of these ligands is in large part due to the ease with which the steric and electronic environment of the coordinated metal centers can be tuned by incorporating substituents on the pyrazolyl ring units. Building tripodal ligands that contain heavier main group element bridgeheads (beyond the second period) potentially enables the systematic modification of donor properties, such as ligand bite and 6donor/ $\pi$-acceptor character, as well as the potential introduction of novel reactivity at the bridgehead atom (such as redox chemistry, where metallic or semi-metallic bridgeheads are involved).

Although less well studied than their tris-pyrazolyl borate relatives, Group 14 and 15 tris-2-pyridyl ligands containing nonmetallic bridgeheads have been known for a number of years (Fig. 1b). ${ }^{[8-10]}$ Our focus in this area has been the exploration of

[a] Mr A. J. Plajer, Dr A. L Colebatch, Mr F. J. Rizzuto, Dr A. D. Bond, Prof. Dr D. S. Wright, Department of Chemistry, University of Cambridge, Lensfield Road, Cambridge CB2 1EW; dsw1000@cam.ac.uk

[b] Mr P. Proehm, Institut fuer Chemie und Biochemie, Freie Universitaet Berlin, Fabeckstr. 34 -36 14159 Berlin

[c] Dr R. Garcia-Rodriguez, GIR MIOMeT-IU Cinquima-Química Inorgunica Facultad de Ciencias, Universidad de Valladolid; Campus Miguel; Delibes, 47011 Valladolid; raul.garcia.rodriguez@uva.es the reactivity and coordination chemistry of Group 13 and 14 tris-2-pyridyl ligands in which metallic or semi-metallic elements are present (like the aluminate shown in Fig. 1c). ${ }^{[11-24]}$

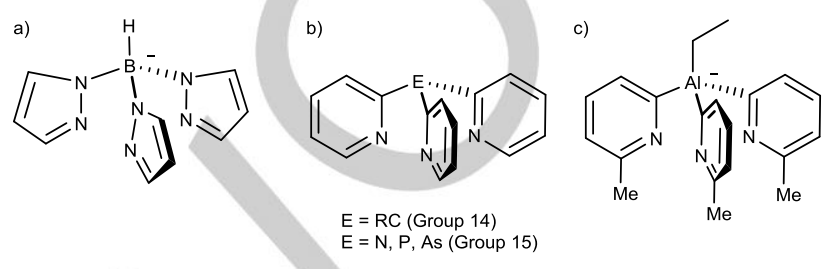

Figure 1 a) The tris-pyrazolyl borate anion, b) the neutral tris-2-pyridyl ligands and c) a tris-2-pyridyl aluminate anion.

Despite the ongoing interest in expanding classical tripodal ligand sets, such as tris-pyrazolyl borate and tris-2-pyridy ligands, no studies have managed to decipher the actual effects of changing the size and electronic character of the bridgehead on structure and reactivity. The preparation of the neutral valence-isolelectronic tris-pryridyl ligands $\left[E(2-\mathrm{Me}-\mathrm{py})_{3}\right](\mathrm{E}=\mathrm{As}$, $\mathrm{Sb}, \mathrm{Bi}$ ) has allowed us to explore this issue for the first time on a single class of main group ligands of this type.

Surprisingly, there are no reports of the synthesis or coordination chemistry of tris-2-pyridyl ligands of $\mathrm{Sb}$ or $\mathrm{Bi}$. Our attempts to obtain the unsubstituted ligands $\mathrm{E}(2-\mathrm{py})_{3}(\mathrm{E}=\mathrm{Sb}, \mathrm{Bi})$ using the in situ reaction of 2-lithio-pyridine with $\mathrm{ECl}_{3}$ were only successful for $E=A s,{ }^{[25]}$ apparently as a result of reductive elimination of bipyrdine from $\mathrm{E}(2-\mathrm{py})_{3}$ and the generation of elemental Sb or Bi for the heavier Group 15 elements. This is in line with a previous report which showed that the ligand $\mathrm{Bi}(2-p y)_{3}$ could not be obtained even from the reaction of $\mathrm{BiCl}_{3}$ with the more stable 2-( $\mathrm{ZnBr})$-pyrdine reagent. ${ }^{[26]} \mathrm{A}$ very recent study also failed to isolate the tris-pyrazolato bridged bismuth ligand. ${ }^{[27]}$ However, use of 2-lithio-6-methyl-pyridine has allowed us here to synthesize the tripodal ligands $E(6-M e-2-p y)_{3}[E=A s$ (1), Sb (2), Bi (3)] in good yields (64-69\%) after crystallisation from toluene (see Scheme 1 and Supporting Information). Bi(6$\mathrm{Me}-2-\mathrm{Py})_{3}(3)$ is the heaviest member of the family of isovalent tris-2-pyridyl main group ligands to be reported. The increased stability of the pyridyl substituents in $\mathbf{2}$ and $\mathbf{3}$ can be ascribed to the electron donating effect of the Me-group, which suppresses reductive elimination. The solid-state structures of 1,2 and 3 (Fig. 2a) are similar to the previously structurally characterised $\mathrm{P}$-counterpart $\mathrm{P}(6-\mathrm{Me}-\mathrm{Py})_{3},{ }^{[15]}$ in which the 6 -Me groups and $\mathrm{N}$ atoms of the pyridyl ring units are orientated ('upwards') towards the lone pair on $\mathrm{E}$. As expected, the $\mathrm{C}_{\text {pyridyr }} \mathrm{E}$ distances increase moving down Group 15 (by ca. $0.29 \AA$ ), matching the increase in atomic size of the Group 15 atoms. 


$$
\begin{array}{lll}
\text { unidentified } \\
\text { byproducts }
\end{array}
$$

Scheme 1 Top: Attempted synthesis of $E(6-M e-P y)_{3}$ with 2-lithio-pyridine $(E=$ $\mathrm{Sb}, \mathrm{Bi})$; this is successful for $\mathrm{E}=\mathrm{As}$. Bottom: synthesis of $\mathrm{E}(6-\mathrm{Me}-\mathrm{Py})_{3}(\mathrm{E}=\mathrm{As}$ $\mathrm{Sb}, \mathrm{Bi})$.

Our initial interest in 1-3 focused on the potential structural/functional effects of the increasing Lewis acidity of the bridgehead as Group 15 is descended. At the top of the group $(\mathrm{N}$ and $\mathrm{P}$ ) the higher electronegativity, combined with the presence of compact lone pairs, is known to lead to ambidentate character in which both the $\mathrm{N}$-atoms of the 2-py groups and the Group 15 atom (E) can donate to metal ions (Fig. 2a). ${ }^{[28-31]}$ However, the onset of electropositive character and relativistic stabilisation of the lone pair at $\mathrm{Bi}$ are anticipated to lead to increasing acceptor character for the bridgehead as the group is descended (Fig. 2b). ${ }^{[31-33]}$ The increase in the Lewis acidity of the bridgehead atoms in 1-3 was demonstrated by initial DFT (B3LYP/def2-TZVPP) calculations of their fluoride ion affinities (see Supporting Information). Thus, we reasoned that the $\mathrm{Sb}$ and $\mathrm{Bi}$ ligands might be capable of simultaneous anion and cation coordination of metal salts. a)

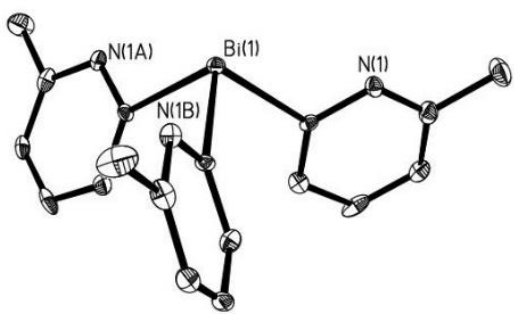

b)

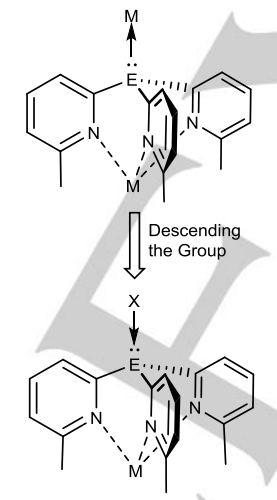

Figure 2 a) The common solid-state molecular structure of $E(6-\mathrm{Me}-2-\mathrm{Py})_{3}(\mathrm{E}=$ $\mathrm{As}, \mathrm{Sb}, \mathrm{Bi}$ ) (the structure shown is that of $\mathbf{3}$ ). Displacement ellipsoids are set at $30 \%$ probability. $\mathrm{H}$-atoms have been omitted for clarity. For selected bond lengths and angles for 1-3 see Supporting Information. b) The on-set of electropositive character of the Group 15 bridgehead, donor-N/donor-E to donor-N/acceptor E.

The $\mathrm{Cu}^{\prime}$ complexes $\left[\mathrm{E}(6-\mathrm{Me}-2-\mathrm{Py}){ }_{3} \mathrm{Cu}(\mathrm{MeCN})\right] \mathrm{PF}_{6}[\mathrm{E}=\mathrm{As}$ (4), $\mathrm{Sb}(5), \mathrm{Bi}(6)]$ were obtained from the room-temperature reactions of 1-3 with $\left[\mathrm{Cu}(\mathrm{MeCN})_{4}\right] \mathrm{PF}_{6}$ in $\mathrm{CH}_{3} \mathrm{CN}$ (Scheme 2). All of the complexes contain iso-structural $[\mathrm{E}(6-\mathrm{Me}-2$ $\left.\mathrm{Py}){ }_{3} \mathrm{Cu}(\mathrm{MeCN})\right]^{+}$cations in the solid state, in which the trispyridyl ligands coordinate pseudo-tetrahedral $\mathrm{Cu}^{\prime}$ centers via all three $\mathrm{N}$-atoms (see Supporting Information). The increase in the size of the bridgehead atom has only a minor influence on the $\mathrm{Cu}^{\prime}$ geometry because the ligand bite is maintained in 1-3 by the combined effects of the reduction of the $\mathrm{C}_{\text {pyridyr }} \mathrm{E}-\mathrm{C}_{p y r i d y l}$ angle from $\mathrm{As}$ to $\mathrm{Bi}$, and the pivoting of the 6-Me-2-py groups towards the metal ions (about the ipso-C-atoms of the pyridyl rings). An important consequence of this, in regard to later catalytic sudies, is that the steric environments of the $\mathrm{Cu}^{\prime}$ centers in 4-6 are very similar.

A more noticeable structural influence, however, is the increase in Lewis acidity of the Group 15 bridgehead atoms, resulting in increasing anion-cation interactions on descending Group 15. In the As derivative 4 there are no close contacts between the As ${ }^{\text {III }}$ bridgehead and the $\mathrm{PF}_{6}^{-}$anions in the crystal structure. However, in the $\mathrm{Sb}$ derivative (5), and the isostructural $\mathrm{Bi}$ derivative (6), the structures more clearly contain ion-pairs of the $\left[\mathrm{E}(6-\mathrm{Me}-2-\mathrm{py}){ }_{3} \mathrm{Cu}(\mathrm{MeCN})\right]^{+}$cation and $\mathrm{PF}_{6}{ }^{-}$anion, with short $\mathrm{E} \cdots \mathrm{F}$ interactions. In $\mathbf{5}$, the two shortest Sb $\cdots \mathrm{F}$ contacts are 3.480 (3) and 3.964(4) $\AA$ [cf. a maximum of ca. $3.53 \AA$ expected for a van der Waals interaction] (see Supporting Information). The extent of these interactions increases further for the $\mathrm{Bi}$ complex 6 , in which the corresponding $\mathrm{Bi} \cdots \mathrm{F}$ contacts are 3.343(4) and 3.728(5) $\AA$ (see Supporting Information) [cf. a maximum of $3.77 \AA$ for a van der Waals interaction].

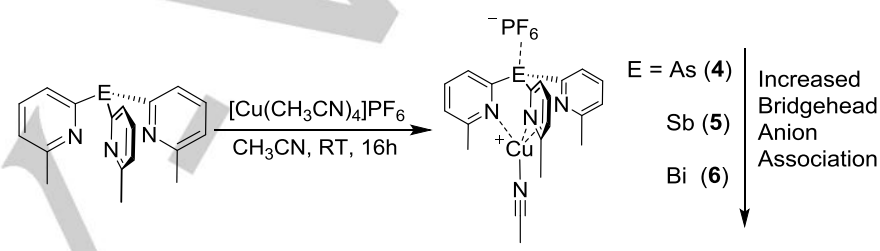

Scheme 2 Synthesis and structural trend observed in the solid-state structures of 4, 5 and 6. Selected bond lengths and angles for 4-6 are included in Supporting Information.

In light of the observed effects of ion-pairing found in the solid-state structures of complexes $\mathbf{5}$ and $\mathbf{6}$, we were intrigued by the potential effects of having a more strongly coordinating anion. Accordingly, we prepared the corresponding $\mathrm{CuCl}$ complexes by the reaction of $\mathrm{CuCl}$ with 2 or 3 in $\mathrm{MeCN}$. As expected, $\mathrm{Sb}(6-\mathrm{Me}-\mathrm{Py})_{3}$ (2) forms a $C_{3 \mathrm{v}}$-symmetric complex (7) in which all three pyridyl groups coordinate to the $\mathrm{Cu}^{\prime}$ ion of a $\mathrm{CuCl}$ unit (Fig. 3a). However, an unprecedented dimeric arrangement [(6-Me-Py)Bi(6-Me-Py $\left.)_{2} \mathrm{CuCl}\right]_{2}(\mathbf{8})$ is observed for 3 , in which one of the intramolecular $\mathrm{N}-\mathrm{Cu}$ bonds is effectively sacrificed for an intermolecular $\mathrm{Cu}-\mathrm{Cl} \cdots \mathrm{Bi}$ interaction, leaving the Cu centers in trigonal planar coordination environments (Fig. 3b). This interaction [3.432(2) $\AA$ ] is around $0.7 \AA$ shorter than the sum of the van der Waals radii of $\mathrm{Bi}$ and $\mathrm{Cl}^{[34]} \mathrm{A}$ single-point DFT calculation (B3LYP hybrid functional, def2-TZVPP basis set) shows that the inter-dimer $\mathrm{Bi} \cdots \mathrm{Cl}$ interactions result from $\mathrm{Cl}$ lone-pair donation into the $\sigma^{*}$-orbital of one of the $\mathrm{C}_{\text {pyridy }}-\mathrm{Bi}$ bonds (See Supporting Information). Additionally, AIM analysis reveals bond critical points in the $\mathrm{Bi} \cdots \mathrm{Cl}$ axes between the monomers (see Supporting Information). These calculations also show that despite the presence of a short intramolecular $\mathrm{Bi} \cdot \cdot \mathrm{Cu}$ contact of ca. $3.27 \AA$ in the monomer units of $\mathbf{8}$, there is no metal-metal bonding. 
a)

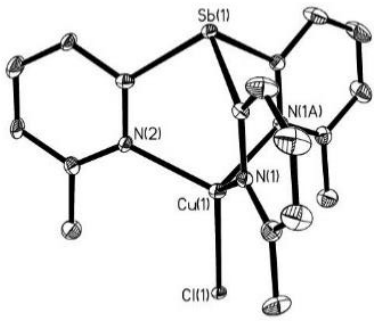

b)

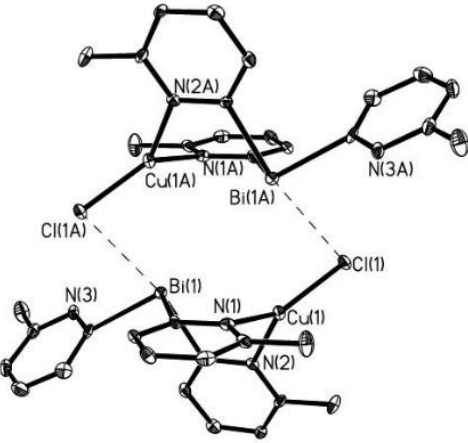

Figure 3 Solid-state structures of (a) [Sb(6-Me-Py) $\left.{ }_{3} \mathrm{CuCl}\right](7)$ and (b) [(6-Me$\left.\mathrm{Py}) \mathrm{Bi}(6-\mathrm{Me}-\mathrm{Py})_{2} \mathrm{CuCl}\right]_{2}$ (8). $\mathrm{H}$-atoms have been omitted for clarity. Displacement ellipsoids are set at $30 \%$ probability. For selected bond lengths and angles see Supporting Information.

The anion-mediated switching of the coordination mode of the tris-2-pyridyl ligand 3 from tris-N-donor in the $\mathrm{CuPF}_{6}$ complex 6 to bis-N-donor/Bi-acceptor in $\mathbf{8}$ is not just a solid-state effect, but can be demonstrated by the addition of an excess of a chloride source (tetrabutylammonium chloride, TBACl) to 6 in $\mathrm{MeCN}$, which gives 8 quantitatively (Scheme 3). Variabletemperature ${ }^{1} \mathrm{H}$ NMR spectroscopic studies $(253-313 \mathrm{~K})$ show that 8 is involved in a monomer/dimer equilibrium in $\mathrm{MeCN}$ solution. In addition to the two sets of 2-pyridyl and Meresonances expected for the $\mathrm{Bi} / \mathrm{Cu}$-bridging and terminal 6-Me2-py groups of the dimer, the room-temperature ${ }^{1} \mathrm{H}$ NMR spectrum of 8 in $d_{3}-\mathrm{MeCN}$ also shows resonances for the symmetric, tris-chelated monomer $\left[\mathrm{Bi}(6-\mathrm{Me}-\mathrm{Py})_{3} \mathrm{CuCl}\right]$ (i.e., isostructural with 7 , ca $10 \%$ at $298 \mathrm{~K}$ ), with the monomer increasing in abundance at higher temperatures (Scheme 3 ). The presence of an intermolecular monomer-dimer equilibrium is confirmed by dilution experiments at room temperature, in which the equilibrium shifts towards the monomer at lower concentrations and towards the dimer at higher concentrations. Van't Hoff analysis of the variable temperature data yields a dimerization enthalpy of $\Delta \mathrm{H}=-21 \pm 2 \mathrm{~kJ} \mathrm{~mol}^{-1}$ and entropy of $\Delta \mathrm{S}$ $=-61 \pm 6 \mathrm{~J} \mathrm{~mol}^{-1} \mathrm{~K}^{-1}$ (see Supporting Information). These data provide further evidence that the enthalpy gained in forming the dimer outweighs the entropic gain normally associated with the chelate effect at lower temperatures.

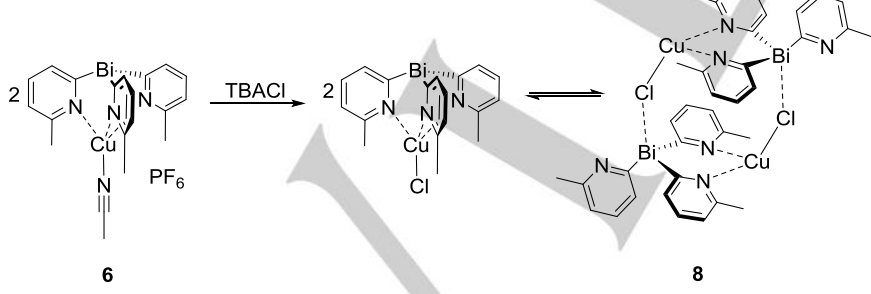

Scheme 3 Equilibrium between monomeric $\left[\mathrm{Bi}(6-\mathrm{Me}-\mathrm{Py})_{3} \mathrm{CuCl}\right]$ and dimeric $\left[(6-\mathrm{Me}-\mathrm{Py}) \mathrm{Bi}(6-\mathrm{Me}-\mathrm{Py})_{2} \mathrm{CuCl}\right]_{2}(8)$.

In addition to structural consequences, ligands 1-3 also provide a unique opportunity to explore the effects of incremental changes in the electronic character and size of the bridgehead on catalytic selectivity and reactivity. The impact of the decrease in electronegativity of the bridgehead atom is

indicated by DFT calculations (B3LYP/def2-TZVPP), which show a small but consistent trend towards greater negative charge at the $\mathrm{N}$-atoms as Group 15 is descended (see Supporting Information). The resulting increase in the $\sigma$-donor character of the ligands is consistent with the trend towards lower $\mathrm{Cu}^{\prime} / \mathrm{Cu}^{\prime \prime}$ oxidation potential observed in the cyclic voltammograms of the $\mathrm{CuPF}_{6}$ complexes 4-6 in $\mathrm{MeCN}\left[\mathrm{E}_{1 / 2}\left(\mathrm{Cu}^{\prime} / \mathrm{Cu}^{\prime \prime}\right)=0.65(4) ; 0.56\right.$ (5); 0.48 (6) V vs. Fc/Fc'] (see Supporting Information). At the same time, the bridgehead atom appears to have little effect on the acceptor character of the ligands, with the free ligands all exhibiting a $\pi$ to $\pi^{*}$ transition at $270 \mathrm{~nm}$ in their UV-visible spectra in DCM (see Supporting Information). This stems from the predominantly $s$-character of the bridgehead $(E)$ lone pairs, which do not have the correct symmetry to interact with the $\pi$ orbitals of the pyridyl rings.

As mentioned previously, facially coordinating tripodal ligands are among the most commonly used auxiliary ligands in homogenous catalysis. In order to probe the way in which the electronegativity of the bridgehead atom affects reactivity we investigated the bridgehead influence on the $\mathrm{Cu}^{\prime}$-mediated aziridination of styrenes. This reaction has been used previously as a mechanistic probe using $\mathrm{Cu}^{\prime}$ tris-pyrazolyl-borate complexes by Perez and coworkers, who showed that the polar contribution to the mechanism is increased by electron-poor $\mathrm{Cu}^{\prime}$ centers, while the radical contribution is increased by electron rich $\mathrm{Cu}^{\prime}$ centers. ${ }^{[35]}$ In this case electronic modulation is achieved by conventional substitution of the pyrazolyl rings. We conducted a similar competitive study of the $\mathrm{Cu}^{\prime}$-mediated aziridination of a series of aryl alkenes 9 with $\mathrm{TsN}=\mathrm{IPh}$ in the presence of styrene, using the $\mathrm{CuPF}_{6}$ complexes $\mathbf{4}, \mathbf{5}$ and $\mathbf{6}$ as the catalysts (Scheme 4). A change in the ratio of the two aziridine products is observed for a given $X$-group $(X=\mathrm{MeO}, \mathrm{Me}$, $\mathrm{Ph}, \mathrm{H}, \mathrm{Cl}, \mathrm{CF}_{3}$ ) moving from 4 to 6 . Hammett analysis of the ratio of the two aziridination products produced $\left(k_{X} / k_{H}\right)$ shows that while the data employing 4 can be fitted well to a singleparameter Hammett equation $\left(\log \left(k_{\mathrm{x}} / k_{\mathrm{H}}\right) v s \sigma^{+}\right)$, the data for $\mathbf{5}$ and 6 as the catalyst are modelled better using a two-parameter equation $\left(\log \left(k_{\mathrm{x}} / k_{\mathrm{H}}\right)\right.$ vs $\left.\sigma^{+}+\sigma^{*}\right)$ (see Supporting Information). This is consistent with a shift from a polar mechanism for $\mathbf{4}$ towards a radical mechanism for $\mathbf{5}$ and $\mathbf{6}$, and is in line with the decrease in the $\mathrm{Cu}^{\prime} / \mathrm{Cu}^{\prime \prime}$ oxidation potentials from $\mathbf{4}$ to $\mathbf{6}$, the decrease in electronegativity of the bridgehead atom, and the resulting increase in $\sigma$-donor character of ligands 1-3 (predicted by DFT calculations). Thus, changing the bridgehead in $\mathrm{E}(6-\mathrm{Me}-$ $\left.2-\mathrm{Py})_{3} \mathrm{Cu}(\mathrm{MeCN})\right]^{+}$can be used to modulate the electronic character. Using this approach in conjunction with ligand substitution can potentially be used to fine-tune the electronic character of tripodal ligands.

In conclusion, we have obtained the first examples of tris2-pyridyl ligands of $\mathrm{Sb}$ and $\mathrm{Bi}$ by 6-methyl substitution of the pyridyl rings. This has allowed us to assess the effects of incremental periodic changes in the electronic character and size of the bridgehead atom for the first time in this and related classes of tripodal main group ligands. The bridgehead atom does indeed have a considerable effect on structure and reactivity of complexes of $\mathrm{E}(6-\mathrm{Me}-2-\mathrm{Py})_{3}$, with a large influence being the electronegativity of the bridgehead atom and its impact 
on Lewis acidity and $\sigma$-donor character of the ligand set. This is seen in the unique, anion-dependent coordination character of the $\mathrm{Bi}(6-\mathrm{Me}-2-\mathrm{Py})_{3}$ ligand, and in the ability to modify the catalytic reactivity by altering the bridgehead atom. Ongoing studies are aimed at developing anion sensing in this area as well as probing new aspects of selectivity and control in catalytic systems.

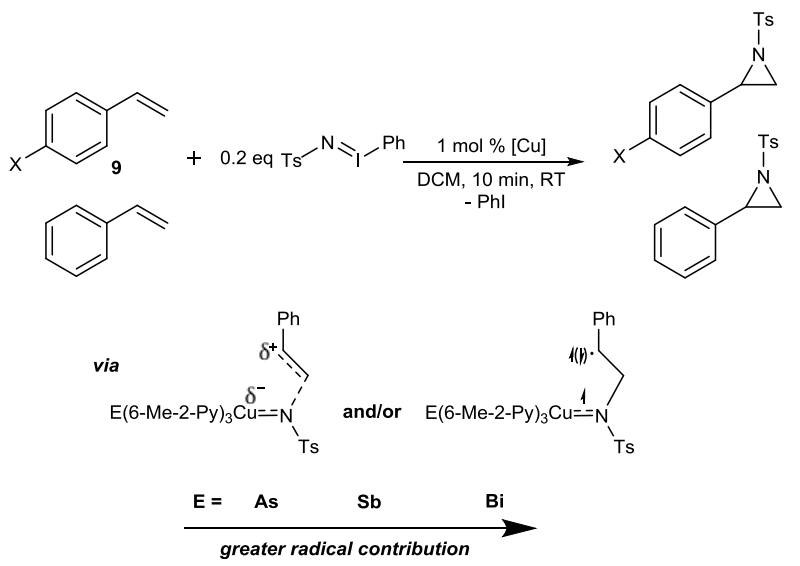

Scheme 4 Competitive catalytic studies of the aziridination of a series of alkenes in the presence of equimolar styrene, using [E(6-Me$\left.\mathrm{Py})_{3} \mathrm{Cu}(\mathrm{MeCN})\right] \mathrm{PF}_{6}[\mathrm{E}=\mathrm{As}(4), \mathrm{Sb}(5), \mathrm{Bi}(6)]$ as the catalyst. $\mathrm{X}=\mathrm{MeO}, \mathrm{Me}$, $\mathrm{Ph}, \mathrm{H}, \mathrm{Cl}, \mathrm{CF}_{3}$.

\section{Acknowledgements}

We thank The Leverhulme Trust (Grant for DSW and RG-R, postdoctoral fundng for ALC), The Spanish MINECO-AEI and The EU (ESF) for a Ramon y Cajal contract (RG-R, RYC-201519035) and The Cambridge Trust (Vice Chancellor Scholarship for AJP, Cambridge Australia Scholarship for FJR) for financial support. We also thank the ZEDAT and FU Berlin (PP). The authors declare no conflict of interest

Keywords: main group synthesis $\bullet$ ligands $\bullet$ tripodal $\bullet$ catalysis $\bullet$ pnictogen

[1] P. H. L. H. Gade, Molecular Catalysis: Structure and Functional Design, WILEY VCH Verlag, Weinheim Germany, 2014.

[2] C. Moberg, Angew. Chemie Int. Ed. 1998, 37, 248-268.

[3] C. Vogel, F. W. Heinemann, J. Sutter, C. Anthon, K. Meyer, Angew.

[4] C. Dro, S. Bellemin-Laponnaz, R. Welter, L. H. Gade, Angew. C. Dro, S. Bellemin-Laponnaz, R. Welter,
Chemie Int. Ed. 2004, 43, 4479-4482.

[5] N. L. Lampland, M. Hovey, D. Mukherjee, A. D. Sadow, ACS Catal. 2015, 5, 4219-4226.

[6] A. G. Walden, A. J. M. Miller, Chem. Sci. 2015, 6, 2405-2410.

[7] S. Trofimenko, Chem. Rev 1993, 93, 943-980.

[8] L. F. Szczepura, L. M. Witham, K. J. Takeuchi, Coord. Chem. Rev. 1998, 174, 5-32.

[9] A. Steiner, D. Stalke, Organometallics 1995, 14, 2422-2429.

[10] H. Tinnermann, C. Wille, M. Alcarazo, Angew. Chemie Int. Ed. 2014, 53, 8732-8736.

[11] H. R. Simmonds, D. S. Wright, Chem Commun 2012, 48, 8617 .

[12] F. Reichart, M. Kischel, K. Zeckert, Chem - A Eur. J. 2009, 15 10018-10020.

[13] C. Cui, R. A. Lalancette, F. Jäkle, Chem. Commun. 2012, 48, 6930.

[14] K. Zeckert, Organometallics 2013, 32, 1387-1393.
S. Hanf, R. García-Rodríguez, A. D. Bond, E. Hey-Hawkins, D. S. Wright, Dalt. Trans. 2016, 45, 276-283.

K. Nishide, S. Ito, M. Yoshifuji, J. Organomet. Chem. 2003, 682, 7984.

X.-K. Wan, Z.-W. Lin, Q.-M. Wang, J. Am. Chem. Soc. 2012, 134, $14750-14752$.

K. Zeckert, S. Zahn, B. Kirchner, Chem. Commun. 2010, 46, 2638. I. Schrader, K. Zeckert, S. Zahn, Angew. Chemie Int. Ed. 2014, 53, 13698-13700.

C. S. Alvarez, F. García, S. M. Humphrey, A. D. Hopkins, R. A. Kowenicki, M. McPartlin, R. A. Layfield, R. Raja, M. C. Rogers, A. D.

Woods, et al., Chem. Commun. 2005, 0, 198-200.
R. García-Rodríguez, D. S. Wright, Dalton Trans. 2014, 43, 1452914532.

R. García-Rodríguez, D. S. Wright, Chem. - A Eur. J. 2015, 21 , 14949-14957.

R. García-Rodríguez, H. R. Simmonds, D. S. Wright, Organometallics 2014, 33, 7113-7117.

R. García-Rodríguez, S. Hanf, A. D. Bond, D. S. Wright, Chem. Commun. 2017, 53, 1225-1228; b) R. Garcia-Rodriguez, S. Kopf and D. S. Wright, Dalton Trans., 2018, 47, 2232-2239.

T. Gneuß, M. J. Leitl, L. H. Finger, N. Rau, H. Yersin, J. Sundermeyer, Dalt. Trans. 2015, 44, 8506-8520.

K. Urgin, C. Aubé, C. Pichon, M. Pipelier, V. Blot, C. Thobie-Gautier, E. Léonel, D. Dubreuil, S. Condon, Tetrahedron Lett. 2012, 53 , 1894-1896.

M.-G. Zhao, T.-T. Hao, X. Zhang, J.-P. Ma, J.-H. Su, W. Zheng, Inorg. Chem. 2017, 56, 12678-12681.

Y. Xie, C.-L. Lee, Y. Yang, S. J. Rettig, B. R. James, Can. J. Chem. 1992, 70, 751-762

G. Zhang, J. Zhao, G. Raudaschl-Sieber, E. Herdtweck, F. E. Kühn, Polyhedron 2002, 21, 1737-1746.

A. Bakhoda, N. Safari, V. Amani, H. R. Khavasi, M. Gheidi, Polyhedron 2011, 30, 2950-2956.

S. Hanf, R. García-Rodríguez, S. Feldmann, A. D. Bond, E. HeyHawkins, D. S. Wright, Dalton Trans. 2017, 46, 814-824.

C. Tschersich, C. Limberg, S. Roggan, C. Herwig, N. Ernsting, S. Kovalenko, S. Mebs, Angew. Chemie Int. Ed. 2012, 51, 4989-4992. T.-P. Lin, I.-S. Ke, F. P. Gabbaï, Angew. Chemie Int. Ed. 2012, 51, 4985-4988.

C. Tschersich, S. Hoof, N. Frank, C. Herwig, C. Limberg, Inorg. Chem. 2016, 55, 1837-1842.

I.-S. Ke, J. S. Jones, F. P. Gabbaï, Angew. Chemie Int. Ed. 2014, 53, 2633-2637.

J. S. Jones, C. R. Wade, M. Yang, F. P. Gabbaï, Dalt. Trans. 2017, 46, 5598-5604.

[34] J. Huyee, E. A. Keiter, R. L. Keiter, Harper Collins, $4^{\text {th }}$ Ed., 1993, pp. A- -25

[35] L. Maestre, W. M. C. Sameera, M. M. Díaz-Requejo, F. Maseras, P. J. Pérez, J. Am. Chem. Soc. 2013, 135, 1338-1348. 


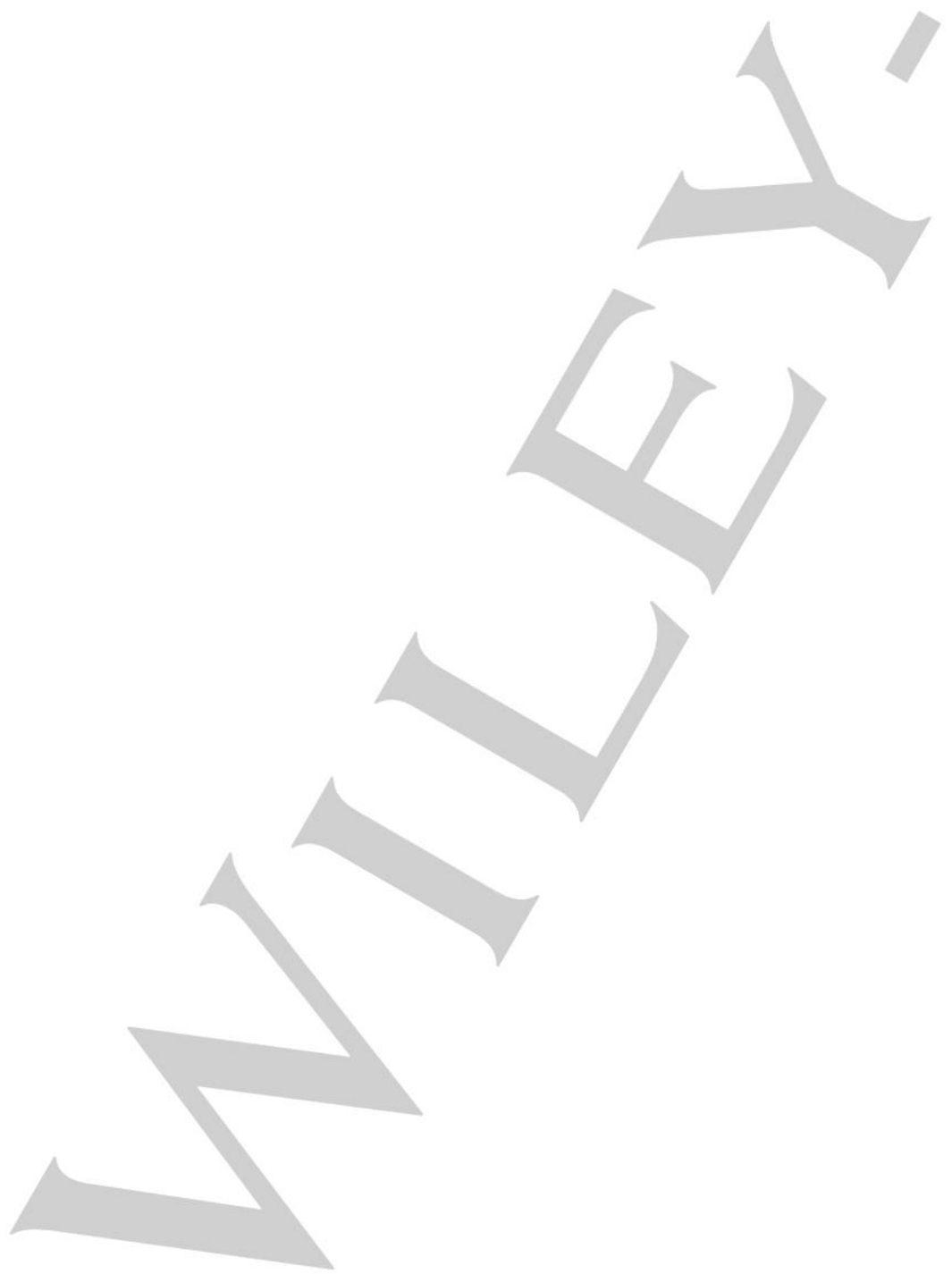

